\title{
Animasi 3D Menjelajah Seluruh Area Untan Menggunakan Navigasi Car Controller
}

\author{
M. Yunus Mandau ${ }^{\text {a1 }}$, Herry Sujaini ${ }^{\text {a2}}$, Hafiz Muhardi ${ }^{\text {a3 }}$ \\ a Program Studi Informatika Universitas Tanjungpura \\ Jl. Prof. Dr. H. Hadari Nawawi, Pontianak 78124 \\ ${ }^{1}$ myunusmandau@gmail.com \\ ${ }^{2}$ hs euntan.ac.id \\ 3hafizmeinformatika.untan.ac.id
}

\begin{abstract}
Abstrak
Universitas Tanjungpura Pontianak memiliki gedung-gedung yang tersebar pada beberapa tempat dalam area kampus yang cukup luas. Mahasiswa baru, pengunjung dan tamu sering merasa kesulitan mencari gedung-gedung di area kampus Universitas Tanjungpura. Untuk memudahkan pencarian gedung maka dibuatlah animasi 3d menjelajah area Universitas Tanjungpura beserta navigasi car controller di Android menggunakan aplikasi blender dan unity. Blender dan unity menjadi software utama dalam proses pembuatan aplikasi menjelajah area Universita Tanjungpura ini. Blender dan unity merupakan software animasi 3D yang mempunyai kemampuan untuk membuat rancang bangun animasi serta menambahkan fungsi car controller secara interaktif. Penelitian ini menghasilkan gambaran area gedung Universitas Tanjungpura dalam tampilan animasi 3D. Aplikasi ini kompatibel dengan minimum versi Android 4.1 'jelly bean' (api level 16). Aplikasi berjalan dengan lancar di Android yang memiliki kapasitas ram $3 \mathrm{gb}$. Berdasarkan hasil yang diperoleh dari uji coba kuisioner aplikasi ini menghasilkan bobot nilai 44, sehingga dapat disimpulkan bahwa aplikasi berjalan dengan nilai "sangat baik".
\end{abstract}

Kata kunci: Universitas Tanjungpura, Blender, Unity, Navigasi Car Controller.

\section{D Animation Exploring the Entire Area of the Untan Using the Navigation Car Controller}

\begin{abstract}
Universitas Tanjungpura Pontianak has well-known buildings in several places within the campus area which is quite large. New students, visitors, and guests often have difficulty finding buildings in the Tanjungpura University campus area. To make it easier to find buildings, a $3 \mathrm{~d}$ animation was created exploring the area of Tanjungpura University along with navigating the car controller on Android using the blender and unity applications. Blender and unity are the main software in the process of making an application to explore the Tanjungpura Universita area. Blender and Unity are 3D animation software that can create animation designs and add interactive car controller functions. This research produces an overview of the Tanjungpura University building in a 3D animated display. This app is compatible with a minimum version of Android 4.1 'jelly bean' (API level 16). The application runs smoothly on Android which has a $3 \mathrm{~Gb}$ ram capacity. Based on the results obtained from the application questionnaire trial produces a weighted value of 44 , so it can produce that the application runs with a value of "very good".
\end{abstract}

Keywords: Tanjungpura University, Blender, Unity, Navigasi Car Controller.

\section{Pendahuluan}

Kegiatan administrasi dan belajar mengajar Universitas Tanjungpura (Untan) selalu dilakukan dalam sebuah gedung, namun dikarenakan area Untan yang cukup luas seringkali membuat mahasiswa khususnya mahasiswa baru merasa kebingungan untuk mengetahui gedung-gedung yang ada. Oleh karena itu gambaran gedung dan area Untan sangat diperlukan, selain untuk mempermudah mahasiswa menemukan Gedung yang ingin dicari, gambaran gedung juga dapat membantu untuk mengetahui area sekitar gedung.

Teknologi saat ini mampu membuat gambaran Gedung dengan sebuah rancang bangun animasi 3D beserta car controller menggunakan aplikasi blender dan unity. Blender dan unity merupakan software animasi 3D, mempunyai kemampuan untuk membuat rancang bangun animasi beserta car controller secara interaktif dan menarik dengan fitur animasi nya [1]. Aplikasi ini juga dapat membuat gambaran sebuah Gedung secara detail dalam bentuk $3 \mathrm{D}$, sehingga pengguna merasa seolah-olah sedang 
berada di gedung yang asli. Dengan desain antarmuka yang sederhana diharapkan pengguna merasa lebih user friendly serta lebih mudah untuk menemukan gedung yang ada di Universitas Tanjungpura (Untan).

Penelitian mengembangkan apilikasi animasi 3D menjelajah seluruh area Untan menggunakan car controller untuk memberikan gambaran gedung Untan kepada mahasiswa. Tujuan pengembangan aplikasi ini adalah agar mahasiswa maupun calon mahasiswa baru dapat lebih mudah mengetahui posisi gedung-gedung yang ada di area Untan.

\section{MEtodologi}

\section{A. Metodologi Penelitian}

Langkah-langkah penelitian yang dilakukan dalam proses pembuatan aplikasi ini sebagai berikut:

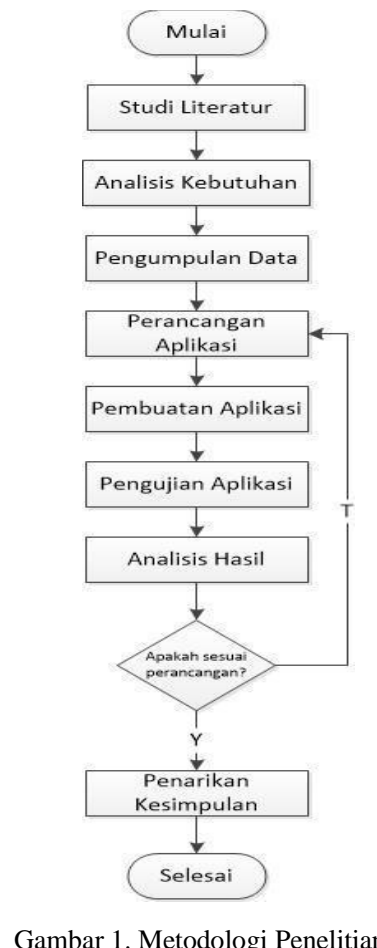

\section{B. Studi Litelatur}

1) Animasi: Animasi adalah gambar yang bergerak dan terbentuk dari sekumpulan objek gambar yang disusun beraturan mengikuti pergerakan yang telah ditentukan pada setiap pertambahan hitungan waktu yang terjadi [2]. Gambar atau objek yang dimaksud dalam definisi di atas bisa berupa gambar manusia, hewan, maupun tulisan [3] Sebenarnya animasi adalah transformasi objek yang diubah sesuai dengan aturan tertentu. Dibandingkan animasi non interaktif, animasi interaktif memberikan tampilan yang lebih menarik dan dinamis. Pada animasi interaktif, pergerakan objek mengikuti perintah yang diberikan oleh pemakai lewat perangkat interaktif. Sedangkan animasi non interaktif, pergerakan objek hanya dikendalikan dari prosedur yang ada di dalam sebuah program [4]. Untuk animasi interaktif kebanyakan digunakan untuk programprogram permainan, sedangkan animasi non interaktif kebanyakan untuk melakukan simulasi objek [5]. Komputer digital yang berkembang pesat sangat mempengaruhi proses pengerjaan animasi. Berdasarkan defenisi model tersebut dapat disimpulkan bahwa model adalah suatu abstrak dari suatu sistem yang digunakan untuk mengurangi kompleksitas system.

2) Game: Game merupakan aktifitas terstruktur atau semi terstruktur yang biasanya bertujuan untuk hiburan dan kadang dapat digunakan sebagai sarana pendidikan [6]. Karakterisitik game yang menyenangkan, memotivasi, membuat kecanduan dan kolaboratif membuat aktifitas ini digemari oleh banyak orang [7]. Terdapat manfaat bermain game, yaitu sebagai berikut:

1) Bisa menjadi sarana hiburan yang menyediakan interaksi sosial.

2) Membangun semangat kerja sama atau teamwork ketika dimainkan dengan gamers-gamers lainnya secara multiplayer.

3) Bagi manula (lansia), bisa mengurangi efek kepikunan.

4) Meningkatkan rasa percaya diri dan harga diri anak saat mereka mampu menguasai permainan.

5) Mengembangkan kemampuan dalam membaca matematika, dan memecahkan masalah atau tugas.

6) Membuat anak-anak merasa nyaman dan familiar dengan teknologi terutama anak perempuan, yang tidak menggunakan teknologi sesering anak cowok.

7) Melatih koordinasi antara mata dan tangan, serta skill motorik.

8) Mengakrabkan hubungan anak dan orangtua. Dengan main bersama, terjalin komunikasi satu sama lain.

9) Juga bisa membantu memulihkan kesehatan untuk beberapa kasus penyembuhan.

3) Blender: Blender adalah program 3D dan animasi yang bersifat open source, bebas untuk dikembangkan oleh penggunanya dan dapat didistribusikan kembali serta bersifat Legal [8]. Blender memiliki video compositor dan intergrated game engine. Karya yang dihasilkan tidak ada sifat berbayar kepada developer dan dapat dipublikasikan baik gratis maupun untuk dikomersilkan. Blender merupakan salah satu program modeling 3D dan Animation, tapi Blender mempunyai kelebihan sendiri dibandingkan program modeling 3D lainnya [9]. Kelebihan yang dimiliki Blender adalah dapat membuat game tanpa menggunakan program tambahan lainnya, karena Blender sudah memiliki game engine sendiri.Blender menggunakan openGL sebagai render grafiknya yang dapat digunakan pada berbagai macam sistem operasi seperti Windows, Linux dan Mac OS.

4) Unity 3D: Unity merupakan suatu aplikasi yang digunakan untuk mengembangkan game multi platform yang didesain untuk mudah digunakan. Editor pada Unity dibuat dengan user interface yang sederhana [10]. Unity mendukung semua format file, terutamanya format umum seperti semua format dari art applications [11]. Unity cocok dengan versi 64-bit dan dapat beroperasi pada Mac OS x dan Windows dan dapat menghasilkan game untuk Mac, Windows, Iphone, Ipad dan Android [12]. Aplikasi 
Unity 3D adalah software game engine pengolah gambar, grafik, suara, input, dan lain-lain yang ditujukan untuk membuat suatu game, meskipun tidak selamanya harus untuk game [13]. Contohnya adalah seperti materi pembelajaran untuk simulasi membuat SIM. Kelebihan dari game engine ini adalah bisa membuat game berbasis 3D maupun 2D, dan sangat mudah digunakan [14].

5) Storyboard: Fungsi dari pembuatan storyboard adalah untuk memudahkan dalam menyampaikan ide atau gagasan sebuah cerita kepada orang lain supaya lebih mudah dipahami dengan memberikan penjelasan tentang alur cerita berdasarkan gambaran besar, mulai dari awal cerita, bagian tengah, hingga akhir cerita. Penulisan storyboard sebaiknya diisi unsur visual terlebih dahulu baru kemudian unsur narasi dan audionya yaitu untuk melengkapi hal-hal yang sulit diungkapkan dalam bentuk visual sehingga harus diperkuat dengan narasi dan background audio atau sound FX [15]. Storyboard merupakan deskripsi dari setiap scene yang secara jelas menggambarkan objek multimedia serta perilakunya yang penjelasannya dapat menggunakan simbol maupun teks [9]. Storyboard merupakan serangkaian sketsa dibuat persegi panjang yang menggambarkan suatu urutan (alur cerita) elemenelemen yang dihasilkan untuk aplikasi multimedia [16].

\section{Data Penelitian}

Data yang dikumpulkan untuk menunjang penelitian ini adalah data yang berupa informasi mengenai tata letak area gedung-gedung Untan, seperti foto-foto bangunan asli serta denah-denah bangunan yang ada di Untan,. Hal ini mempermudah untuk proses pembuatan 3D model yang dilakukan di dalam sebuah aplikasi Blender 3D.

\section{Analisis Model}

1) Alat Penelitian: Alat penelitian yang digunakan dalam penelitian ini adalah Storyboard. Storyboard, digunakan untuk menggambarkan urutan alur cerita dari penggunaan aplikasi dan objek-objek multimedia yang digunakan dalam aplikasi penelitian ini. Dengan adanya storyboard proses pembuatan aplikasi ini menjadi lebih teratur serta mendapatkan gambaran tampilan desain antar muka aplikasi yang dikembangkan.

2) Perangkat Keras: Perangkat keras yang digunakan dalam proses pembuatan aplikasi adalah :

1) 1 unit laptop ASUS ROG Convertible dengan spesifikasi berupa Processor Intel Core i7, hardisk 2 TB, dan RAM 8 GB. Laptop ini digunakan sebagai hardware utama dalam pembuatan aplikasi, karena pada laptop ini semua proses pembuatan aplikasi dilakukan. Disarankan minimal RAM 4 GB untuk melakukan pembuatan aplikasi serupa.

2) 1 unit Kamera Canon 200D digunakan untuk melakukan pemotretan gedung-gedung dan area sekitar Untan, bertujuan untuk acuan pembuatan 3D model.
3) Perangkat lunak: Perangkat lunak yang digunakan dalam proses pembuatan aplikasi pada penelitian ini adalah:

1) Sistem Operasi Windows 10 home 64 bit, sebagai sistem operasional pada laptop yang digunakan dalam membuat aplikasi.

2) Adobe After Effects CS 6, sebagai software atau perangkat lunak utama untuk membuat dan mengedit tampilan tekstur di dalam animasi.

3) Blender 3D 2.71, sebagai software yang digunakan untuk pembuatan model-model 3D seperti bangunan, pohon-pohon \& jalan.

4) Unity 3D 2018, sebagai software yang digunakan untuk beberapa hal sebagai berikut :

- Import 3D model dari Blender ke Unity.

- Melakukan penggabungan objek-objek 3D menjadi satu bagian dan di susun sesuai rancangan storyboard.

- Menambahkan fungsi navigasi car controller.

- Launching aplikasi kedalam bentuk format apk, agar dapat diinstall ke dalam Android.

5) 3D Exchange, sebagai software yang digunakan untuk mengubah format $3 \mathrm{~d}$ model ke dalam bentuk format tertentu agar memudah kan eksport file dari Blender ke Unity.

\section{E. Perancangan Pengujian}

Animasi 3D gedung Untan beserta navigasi car controler ini akan diuji menggunakan kuisioner, yaitu membaikan beberapa pertanyaan kepada mahasiswa Untan. Akan ada 6 pertanyaan dan dibagikan kepada 10 orang mahasiswa. Jumlah skor tertinggi untuk setiap pertanyaan yaitu $=5 \mathrm{x}$ $10=50$. Sedangkan jumlah skor terendah yaitu $1 \times 10=10$. Untuk menentukan kategori diperlukan interval terlebih dahulu. Dengan rumus:

$$
\mathrm{I}=\frac{R}{K}
$$

I = Interval

$\mathrm{R}=$ Skor Tertinggi - Skor Terendah

$\mathrm{K}=$ Banyaknya $(\mathrm{n})$ Kategori

Skor akan dibagi kedalam 5 kategori dengan menggunakan skala Likert yaitu :

1. Skor 5 untuk kategori jawaban sangat setuju.

2. Skor 4 untuk kategori jawaban setuju.

3. Skor 3 untuk kategori jawaban netral.

4. Skor 2 untuk kategori jawaban tidak setuju.

5. Skor 1 untuk kategori jawaban sangat tidak setuju.

TABEL I

BOBOT DAN KATEGORI

\begin{tabular}{|c|c|}
\hline Bobot & Kategori \\
\hline $10-14,5$ & Sangat Tidak Cukup \\
\hline $15-19,5$ & Tidak Cukup \\
\hline $20-29,5$ & Cukup \\
\hline $30-39,5$ & Baik \\
\hline $40-50$ & Sangat Baik \\
\hline
\end{tabular}


TABEL III

PERTANYAAN KUISIONER

\begin{tabular}{|l|l|l|l|l|l|}
\hline \multicolumn{1}{|c|}{ Pertanyaan } & SS & S & N & TS & STS \\
\hline $\begin{array}{l}\text { Apakah animasi gedung 3d untan ini } \\
\text { dapat memberikan gambaran } \\
\text { gedung aslinya? }\end{array}$ & & & & & \\
\hline $\begin{array}{l}\text { Apakah dengan adanya car simulator } \\
\text { dapat mempermudah menjelajah } \\
\text { area untan? }\end{array}$ & & & & & \\
\hline $\begin{array}{l}\text { Apakah warna pada animasi sesuai } \\
\text { warrna asli gedung? }\end{array}$ & & & & & \\
\hline $\begin{array}{l}\text { Apakah denah gedung yang dipakai } \\
\text { sesuai dengan denah asli gedung? }\end{array}$ & & & & & \\
\hline $\begin{array}{l}\text { Apakah tampilan animasi gedung } \\
\text { menarik untuk digunakan? }\end{array}$ & & & & & \\
\hline $\begin{array}{l}\text { Apakah animasi gedung Untan ini } \\
\text { mudah untuk digunakan? }\end{array}$ & & & & & \\
\hline
\end{tabular}

\section{HASIL DAN PEMBAHASAN}

\section{A. Hasil}

Aplikasi 3D menjelajah area Untan menggunakan car controller yang telah dibuat ini diimplementasikan secara offline pada Android. Aplikasi ini dibangun dengan menggunakan software Blender 3D, Unity 3D, After Effects dan menghasilkan file yang berekstensi apk sehingga dapat diimplementasikan langsung kedalam Android. Setelah aplikasi di copy paste pada Android selanjutnya kita akan masuk kedalam proses instalasi sebelum mulai menjalankan aplikasi.

\section{B. Hasil Perancangan}

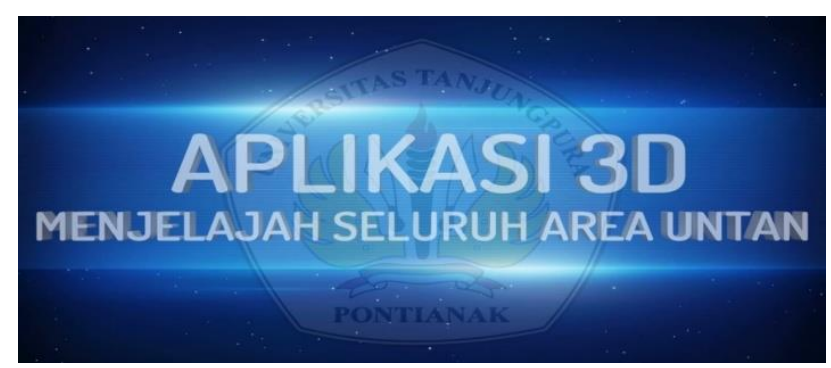

Gambar 2. Antarmuka Scene Screen Flash Opening

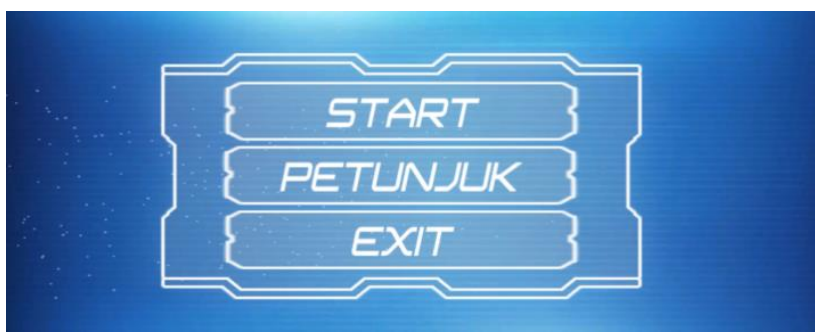

Gambar 3. Antarmuka Scene Menu Utama

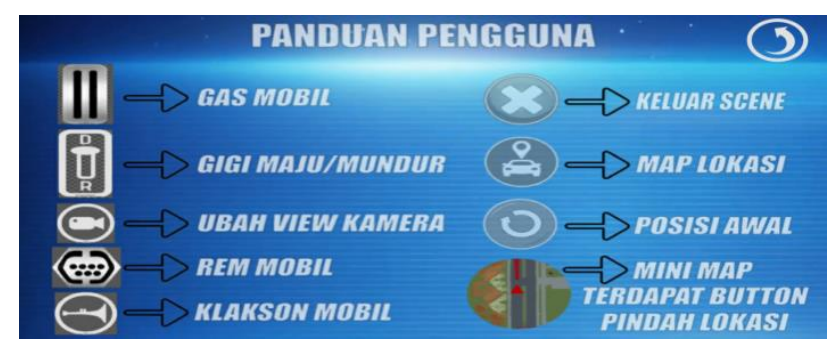

Gambar 4. Antarmuka Scene Petunjuk

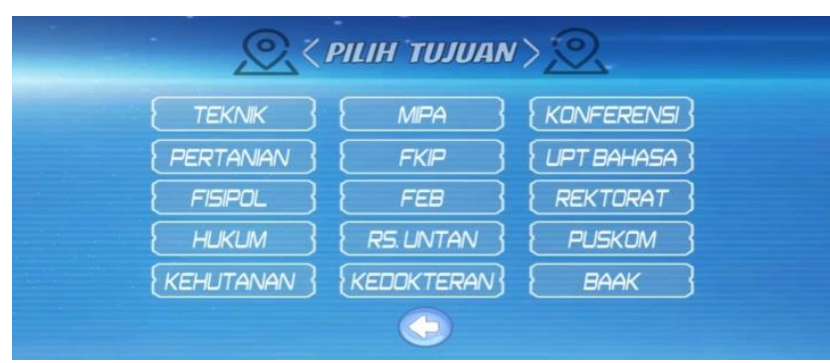

Gambar 5. Antarmuka Scene Titik Lokasi Mobil

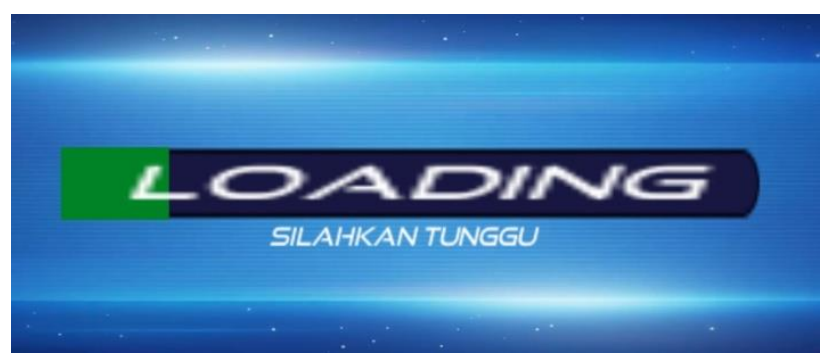

Gambar 6. Antarmuka Scene Titik Lokasi Mobil

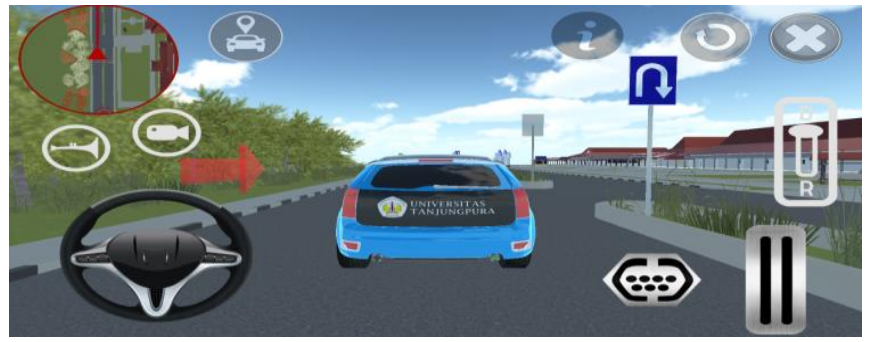

Gambar 7. Antarmuka Posisi Awal Mobil

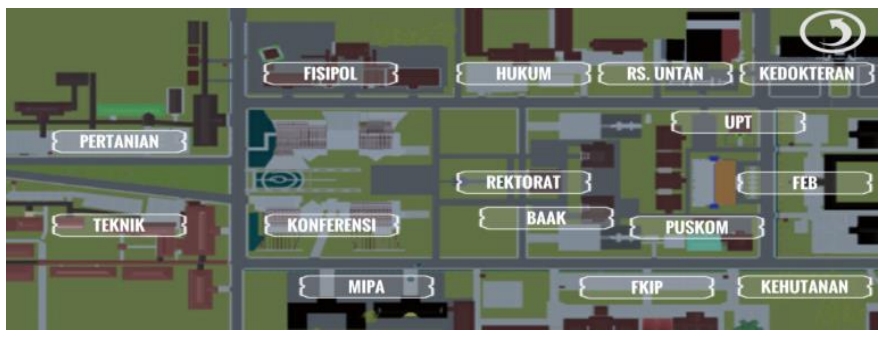

Gambar 8. Antarmuka Map dan Button Nama Lokasi

Compatibility testing merupakan sebuah tahap pengujian aplikasi dengan perangkat mobile yang berbeda dengan ukuran layar yang berbeda pula serta versi OS yang sesuai dengan kebutuhan. Untuk aplikasi menjelajah area Untan 3D ini akan berjalan minimum versi OS Android 4.1 'Jelly Bean' (API level 16), sesuai minimum proses build dari Unity 3D. Aplikasi menjelajah area Untan 3D ini juga akan berjalan dengan lancar di versi Android di atas 4.1 'Jelly Bean' seperti Android 4.2 'Jelly Bean' (API level 17), 4.3 'Jelly Bean' (API level 18), 4.4 'Kit Kat' (API level 19), 5.0 'Lollipop' (API level 21), 5.1 'Lollipop' (API level 22), 6.0 'Marshmallow' (API level 23), 7.0 'Nougat' (API level 24), 7.1 'Nougat' (API level 25) dan seterusnya. Berikut di bawah ini hasil pengujian dari beberapa versi Android. 


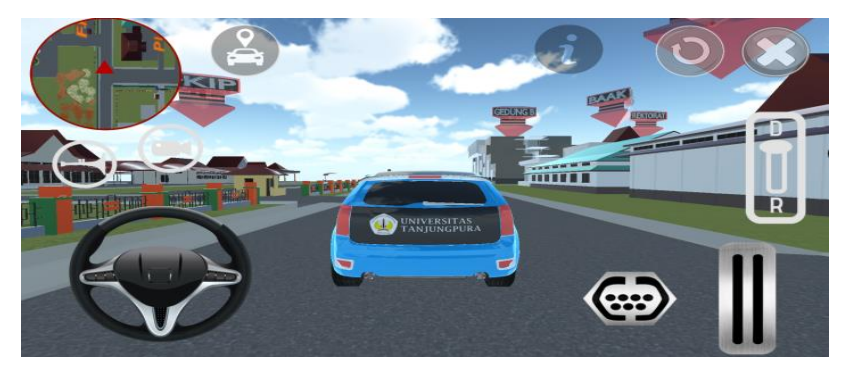

Gambar 9. Antarmuka Compatibility Testing di HP OPPO A37

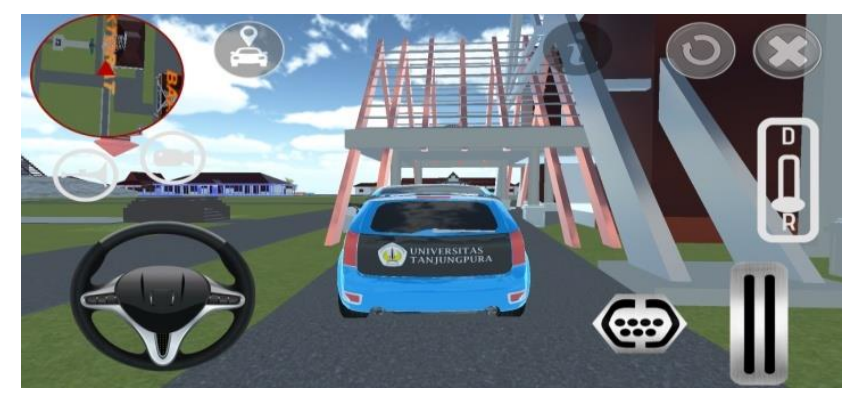

Gambar 10. Antarmuka Compatibility Testing di HP Vivo V5

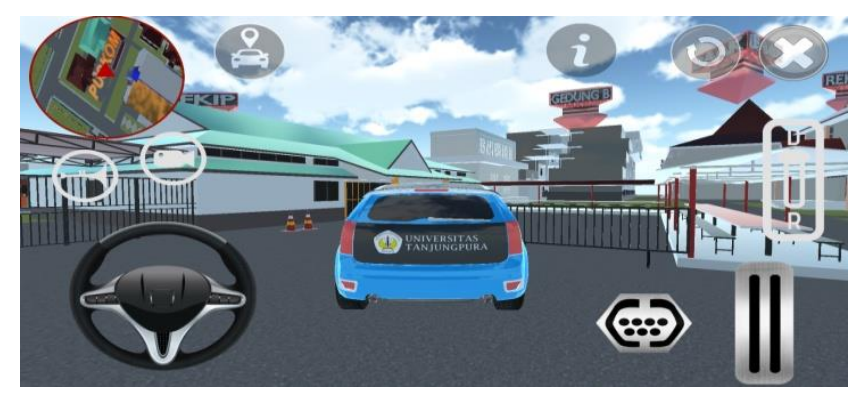

Gambar 11. Antarmuka Compatibility Testing di HP Xiaomi S2

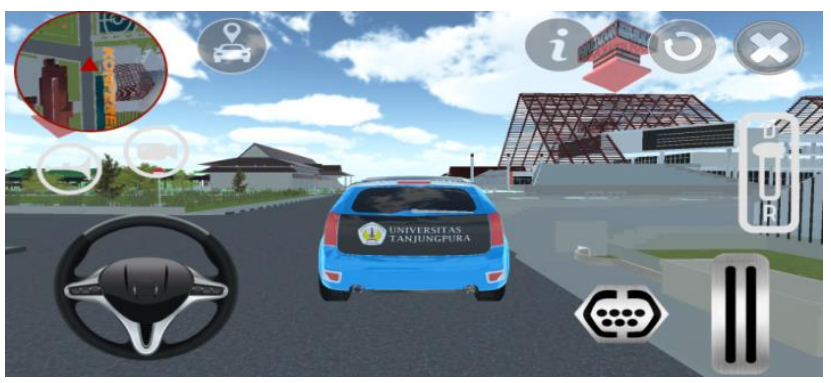

Gambar 12. Antarmuka Compatibility Testing HP Samsung J7 Prime

\section{Hasil Pengujian}

Pengujian dilakukan dengan memberikan pertanyaanpertanyaan mengenai gambaran gedung di Untan dalam bentuk kuestioner, setelah user menggunakan aplikasi 3D ini. Ada enam pertanyaan untuk dijawab oleh sepuluh perserta uji. Jawaban dari pertanyaan berupa sangat setuju, setuju, netral, tidak setuju dan sangat tidak setuju yang masing-masing diberikan botot $5,4,3,2$, dan 1 . Hasil pengujian diberikan pada table IV dan V.
TABEL IIIII

TABEL PENGUJIAN ANIMASI 3D MENJELAJAH AREA UNTAN

\begin{tabular}{|l|c|c|}
\hline \multicolumn{1}{|c|}{ Pernyataan } & Bobot & Kategori \\
\hline $\begin{array}{l}\text { Apakah animasi gedung 3d untan } \\
\text { ini dapat memberikan gambaran } \\
\text { gedung aslinya? }\end{array}$ & 44 & Sangat Baik \\
\hline $\begin{array}{l}\text { Apakah dengan aplikasi ini dapat } \\
\text { mempermudah mengenal \& } \\
\text { menjelajah area untan? }\end{array}$ & 46 & Sangat Baik \\
\hline $\begin{array}{l}\text { Apakah warna pada animasi } \\
\text { sesuai warna asli gedung? }\end{array}$ & 39 & Baik \\
\hline $\begin{array}{l}\text { Apakah denah gedung yang } \\
\text { dipakai sesuai dengan denah asli } \\
\text { gedung? }\end{array}$ & 45 & Sangat Baik \\
\hline $\begin{array}{l}\text { Apakah tampilan animasi gedung } \\
\text { menarik untuk digunakan? }\end{array}$ & 42 & Sangat Baik \\
\hline $\begin{array}{l}\text { Apakah animasi gedung Untan } \\
\text { ini mudah untuk digunakan? }\end{array}$ & 48 & Sangat Baik \\
\hline Rata-rata Bobot = 264 & $\mathbf{4 4}$ & Sangat Baik \\
\hline
\end{tabular}

TABEL IVV

PERHITUNGAN BOBOT ANIMASI 3D MENJELAJAH AREA UNTAN

\begin{tabular}{|c|c|c|c|c|c|c|c|c|}
\hline $\begin{array}{c}\text { Pernya } \\
\text { taan }\end{array}$ & $\mathbf{S}$ & $\mathbf{S}$ & $\mathbf{N}$ & $\mathbf{T}$ & $\mathbf{S}$ & $\begin{array}{c}\text { Perhitungan } \\
\mathbf{\text { Bobot }}\end{array}$ & $\begin{array}{c}\text { Bo } \\
\text { bot }\end{array}$ & Kategori \\
\hline 1 & 4 & 6 & 0 & 0 & 0 & $\begin{array}{c}4(5)+6(4)+0(3) \\
+0(2)+0(1)\end{array}$ & 44 & $\begin{array}{c}\text { Sangat } \\
\text { Baik }\end{array}$ \\
\hline 2 & 6 & 4 & 0 & 0 & 0 & $\begin{array}{c}6(5)+4(4)+0(3) \\
+0(2)+0(1)\end{array}$ & 46 & $\begin{array}{c}\text { Sangat } \\
\text { Baik }\end{array}$ \\
\hline 3 & 2 & 5 & 3 & 0 & 0 & $\begin{array}{c}2(5)+5(4)+3(3) \\
+0(2)+0(1)\end{array}$ & 39 & Baik \\
\hline 4 & 5 & 5 & 0 & 0 & 0 & $\begin{array}{c}5(5)+5(4)+0(3) \\
+0(2)+0(1)\end{array}$ & 45 & $\begin{array}{c}\text { Sangat } \\
\text { Baik }\end{array}$ \\
\hline 5 & 3 & 6 & 1 & 0 & 0 & $\begin{array}{c}3(5)+6(4)+1(3) \\
+0(2)+0(1)\end{array}$ & 42 & $\begin{array}{c}\text { Sangat } \\
\text { Baik }\end{array}$ \\
\hline 6 & 8 & 2 & 0 & 0 & 0 & $\begin{array}{c}8(5)+2(4)+0(3) \\
+0(2)+0(1)\end{array}$ & 48 & $\begin{array}{c}\text { Sangat } \\
\text { Baik }\end{array}$ \\
\hline
\end{tabular}

\section{KESIMPULAN}

Setelah menyelesaikan proses pembuatan Animasi 3D menjelajah area Universitas Tanjungpura beserta navigasi Car Controller berbasis Android ini, dapat diambil kesimpulan bahawa penelitian ini berhasil menghasilkan aplikasi animasi 3D gambaran area Universitas Tanjungpura beserta navigasi car controller berbasis android. Berdasarkan kuisioner, penelitian ini dapat mempermudah pengguna untuk mengetahui gambaran area dan tata letak Gedung-gedung di Universitas Tanjungpura dalam tampilan animasi 3D.

\section{DAFTAR PUSTAKA}

[1] R. Hess, The Essential Blender: Guide to 3D Creation with the Open Source Suite Blender. New York: No Starch Press, 2007. R. Pangemanan, R. Sengkey, and O. A. Lantang, "Perancangan Animasi 3 Dimensi Alur Pengurusan Administrasi Pasien Umum dan Jaminan Dibagian Rehabilitasi Medik RSUP Prof. DR. RD Kandou Manado," J. Tek. Inform., vol. 9, no. 1, 2016.

[3] F. Nugroho, Membuat Animasi Kartu Ucapan dengan Flash 8. Jakarta: PT Elex Media Komputido, 2005. 
[4] G. G. Robertson, S. K. Card, and J. D. Mackinlay, "Information visualization using $3 \mathrm{D}$ interactive animation," Commun. ACM, vol. 36, no. 4, pp. 56-72, 1993.

[5] H. W. Pramana, Aplikasi Inventory Berbasis Access 2003. Jakarta: Elex Media Komputindo, 2012.

[6] W. A. Aeni and M. Kom, "Antara Game, Pendidikan dan HP (Game Mobile Learning Sebagai Wacana Pendidikan)," Diambil dari http://medukasi. net/artikel-mobile-learning-isi. php, 2009.

[7] A. H. Sutopo, Multimedia interaktif dengan flash. Yogyakarta: Graha Ilmu, 2003.

[8] Y. U. L. H. Zuryana, "Visualisasi Tour Guide Universitas Almuslim Berbasis 3d," J. TIKA, vol. 1, no. 2, 2016.

[9] M. V. Rompas, A. Sinsuw, J. Robot, and X. Najoan, "Perancangan Gedung Fakultas Teknik Unsrat Dengan Perspektif Animasi 3D," J. Tek. Inform., vol. 2, no. 2, 2013.

[10] A. K. Pamoedji and R. S. Maryuni, Mudah Membuat Game Augmented Reality (AR) dan Virtual Reality (VR) dengan Unity 3D. Jakarta: Elex Media Komputindo, 2017.

[11] N. Nina Nuriana, "Pengenalan Hewan Menggunakan Augmented Reality Sebagai Media Pembelajaran," J. TIKA, vol 1, no. 3, 2016.

[12] F. Santoso, "Game Simulator Pengenalan Rambu-rambu Lalu Lintas Sebagai Media Pembelajaran Interaktif," 2016.

[13] Y. Caroline, V. Tulenan, and B. A. Sugiarso, "Rancang Bangun Film Animasi 3 Dimensi Universitas Sam Ratulangi," J. Tek. Inform., vol. 9, no. 1, 2016.

[14] D. Utami, "Animasi dalam pembelajaran," Maj. Ilm. Pembelajaran, vol. 7, no. 1, 2011.

[15] F. T. Hofstetter, Multimedia literacy. New York: McGraw-Hill, Inc., 2001.

[16] S. Hermawan, Mudah Membuat Aplikasi Android. Yogyakarta: Penerbit Andi, 2011. 